\title{
Sposób wypływu gazu osłonowego przy metodzie TIG a jakość złącza spawanego
}

\author{
Method of exposure of covering gas with TIG method \\ and quality of weld connector
}

\section{Streszczenie}

W pracy dokonano oceny wpływu turbulentnego i laminarnego wypływu gazu osłonowego na uzyskaną jakość spoiny na podstawie badań nieniszczących. Przeanalizowano aspekty teoretyczne wypływu gazu osłonowego podczas spawania metodą TIG. Przeprowadzono wstępne badania doświadczalne, które potwierdziły wpływ sposobu wypływu z dyszy gazu osłonowego na jakość złączy spawanych.

Słowa kluczowe: metoda TIG; gaz osłonowy; badania nieniszczące; jakość złącza

\begin{abstract}
The work has evaluated the influence of turbulent and laminar covering gas flow on the obtained weld quality on the basis of non-destructive testing. The theoretical aspects of the covering gas flow during TIG welding have been analyzed. Preliminary experimental studies have been carried out which have confirmed the effect of the discharge method from the casing gas nozzle on the quality of welded joints.
\end{abstract}

Keywords: method TIG; cover gas; non-destructive testing; connector quality

\section{Wprowadzenie}

Spawanie metodą TIG (141) ma szerokie zastosowanie mimo wyraźnie niższej wydajności procesu topienia spoiwa i wyższych kosztów stosowanych gazów osłonowych niż spawanie MAG/MIG. Zapewnienie stabilnego procesu spawalniczego i uzyskanie spoin o pożądanym poziomie jakości w tej metodzie w dużej mierze zależy od zapewnienia stabilnej osłony gazowej $[1,2]$.

Metoda TIG polega na spawaniu łukowym w osłonie gazu obojętnego nietopliwą elektrodą z czystego lub aktywnego wolframu, w którym elektroda wolframowa, łuk spawalniczy i jeziorko spawalnicze ochraniane są osłoną gazu obojętnego przed dostępem powietrza. Spawanie odbywa się wyłącznie z zastosowaniem gazu obojętnego, argonu, helu i ich domieszek, niekiedy z dodatkiem wodoru podnoszącego energię łuku spawalniczego. Metoda ta stosowana jest do łączenia wszystkich spawalnych gatunków stali, a także aluminium, magnezu, miedzi, niklu i ich stopów we wszystkich pozycjach. Jednak jedną z jej podstawowych wad jest duża wrażliwość osłony gazowej na zaburzenia tj. podmuchy, wiatry, czy przeciągi $[3,4]$.

Gazy osłonowe są doprowadzane w sposób stały do strefy jarzenia łuku spawalniczego i chronią jeziorko spawalnicze przed dostępem tlenu i azotu z powietrza atmosferycznego, zatem osłaniają płynną spoinę. Tlen oraz azot bardzo łatwo wiążą się z żelazem i składnikami stopów żelaza, tworząc liczne związki chemiczne (tlenki lub azotki), których występowanie w spoinie na ogół pogarsza jej własności użytkowe. Wydatek gazu osłonowego jest związany z jego rodzajem i natężeniem prądu. Przy przeciętnych warunkach spawania wydatek argonu wynosi ok. 8-16 I/min. Nadmierny wydatek powoduje turbulencje i zasysanie powietrza do przestrzeni łuku. Podczas łączenia metali łatwo utleniających się (np. Ti, Zr, niekiedy stali nierdzewnych), korzysta się z dodatkowej osłony grani spoiny lub spawa się w komorach wypełnionych gazem. Gazy osłonowe stosowane podczas spawania metodą TIG zapewniają pełną osłonę elektrody wolframowej i obszaru spawania przed dostępem powietrza atmosferycznego, pod warunkiem, że nie ma wirów na poziomie łuku spawalniczego (turbulentnego wypływu gazu osłonowego) $[1,5]$.

Celem pracy jest próba oceny wpływu turbulentnego i laminarnego wypływu gazu osłonowego na uzyskaną jakość spoiny na podstawie badań nieniszczących.

Mgr inż. Mirosława Wiśniewska; dr hab. inż. Maciej Matuszewski - Uniwersytet Technologiczno-Przyrodniczy w Bydgoszczy. Autor korespondencyjny/Corresponding author. matus@utp.edu.pl 


\section{Charakterystyka sposobów wypływu gazu ochronnego}

Uchwyt do spawania (rys. 1) metodą 141 jest urządzeniem, które doprowadza czynniki konieczne dla procesu spawania - prąd spawania, prąd sterowania, gaz osłonowy i czynnik chłodzący $[1,3,4]$.

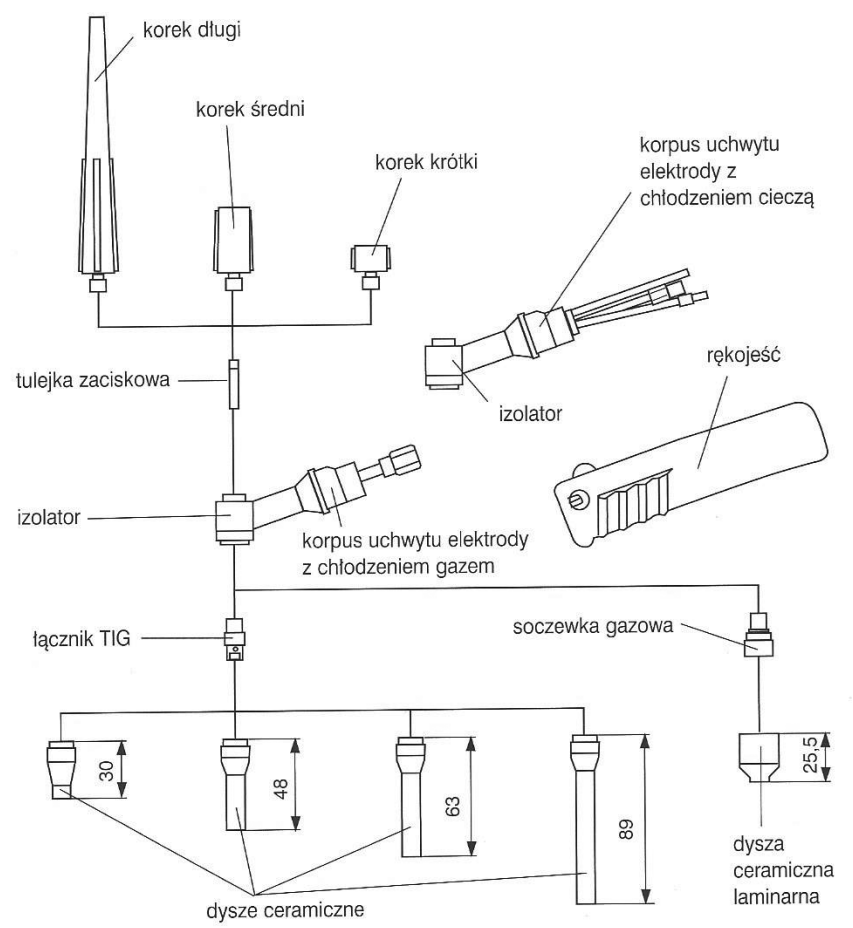

Rys. 1. Uchwyt do spawania metodą TIG [1]

Fig. 1. Handle for TIG welding [1]

Elektroda wolframowa jest umieszczona w dyszy gazowej uchwytu spawalniczego i stanowi jeden biegun źródła prądu spawania. Drugi, przeciwny biegun stanowią spawane elementy. Elektrodę wolframową mocuje się w uchwycie za pomocą tulejki zaciskowej o średnicy odpowiadającej średnicy elektrody. Elektroda jest zaciskana w tulejce za pomocą korka uszczelniającego górną część uchwytu elektrody. Dysza gazowa jest osadzona w dalszej części uchwytu. Do niej doprowadza się gaz osłonowy. Podczas spawania gaz osłonowy wypływa z dyszy i zabezpiecza przestrzeń łuku spawalniczego i jeziorko ciekłego metalu przed zetknięciem z otaczającym powietrzem atmosferycznym. Gaz szlachetny nie wchodzi w reakcje z ciekłym metalem, więc ochrona procesu spawania jest całkowita. Osłona łuku spawalniczego i jeziorka spawalniczego zależy od kształtu dyszy i ilości przepływającego gazu osłonowego [1].

Zadaniem ceramicznej dyszy gazowej jest centryczne i laminarne wyprowadzenie gazu osłonowego z uchwytu. Taki wypływ gazu z uchwytu stosuje się w celu zapewnienia jak największej jakości złącza spawanego. Istotnym elementem uchwytu spawalniczego, który ma wpływ na wyprowadzanie gazu, a tym samym jakość złącza, jest łącznik prądowy lub soczewka gazowa. Na rysunku 2 przedstawiono przykładowy łącznik prądowy.

Łącznik prądowy TIG posiada 3 $\div 4$ otwory, przez które przepływa gaz osłonowy. Otwory z powodu bardzo małej średnicy powodują wzrost ciśnienia gazu i prędkości jego wypływu. Wpływający do dyszy gazowej gaz osłonowy zaczyna odbijać się od jej ścianek, co w efekcie powoduje dostarczenie gazu do jeziorka spawalniczego w sposób turbulentny (rys. 3).

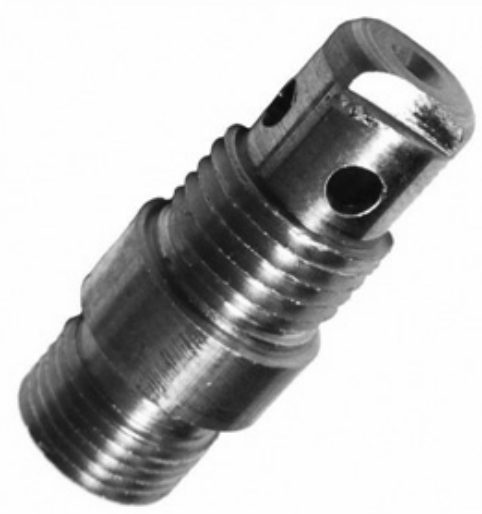

Rys. 2. Łącznik prądowy TIG [6]

Fig. 2. Coupler switch TIG [6]

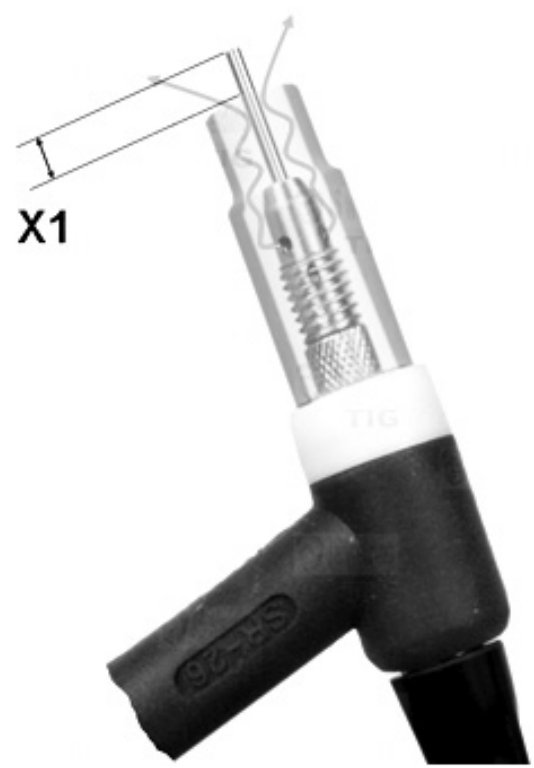

Rys. 3. Schemat wypływu gazu z łącznika prądowego TIG [7] Fig. 3. Scheme of gas outflow from the coupler switch TIG [7]

W celu uniknięcia utlenienia się elektrody wolframowej, ze względu na zaburzony wypływ gazu (turbulentny), konieczne jest zastosowanie określonego wysunięcia elektrody wolframowej $(x 1)$. Wysunięcie to jest mniejsze niż w przypadku zastosowania soczewki gazowej. Przykładowa soczewka przedstawiona jest na rysunku 4.

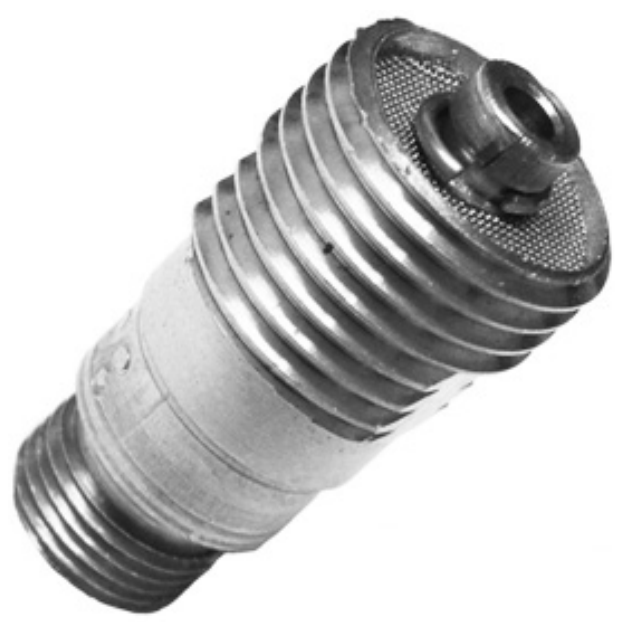

Rys. 4. Soczewka gazowa [6]

Fig. 4. Gas lens [6] 
Soczewka gazowa ma za zadanie stabilizować wypływ gazu z dyszy, czyli zapewniać laminarne wyprowadzanie gazu. Osiąga się to dzięki wbudowanemu filtrowi w formie sitka z wieloma otworami, przez które wypływa gaz osłonowy. Dodatkowo wpływający strumień do dyszy gazowej w postaci jednolitego słupa gazu pozwala na dłuższe wysunięcie elektrody wolframowej, ponieważ gaz dłużej spełnia swoje zadanie (rys. 5).

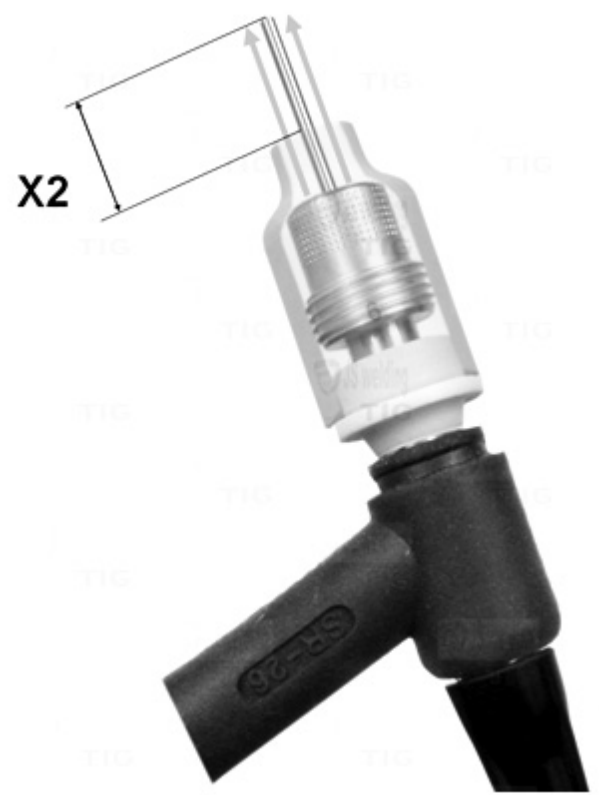

Rys. 5. Schemat wypływu gazu z soczewki gazowej [7] Fig. 5. Scheme of gas outflow from gas lens [7]

Dłuższe wysunięcie elektrody wolframowej (x2), ułatwia obserwację jeziorka spawalniczego podczas spawania i pozwala na dojście do trudno dostępnych miejsc spawania. Przykładem takich złączy spawanych, mogą być np.: m.in. rozgałęzione rury różnych rurociągów (rys. 6) czy zbiorniki $[3,4,8]$.

$\mathrm{Na}$ rysunku 7, przedstawiono symulację wypływu gazu z uchwytów spawalniczych przeznaczonych do spawania metodą TIG uzbrojonych w łącznik prądowy TIG (rys. 7a) oraz soczewkę gazową (rys. 7b).

Wypływ gazu z uchwytu z łącznikiem prądowym jest turbulentny, przyczynia się to do utrudnionej pełnej ochrony elektrody wolframowej oraz jeziorka spawalniczego. Taki przepływ gazu ma również wpływ na uzyskaną jakość złącza spawanego. Zawirowania gazu mogą zasycać powietrze z atmosfery i wprowadzać tlenki oraz azotki do złącza. Natomiast w soczewce gazowej wypływający przez sitko gaz osłonowy jest rozbity na wiele malutkich strumieni, co zapewnia przepływ laminarny i w efekcie tworzy się jeden strumień gazu osłonowego chroniący zarówno elektrodę wolframową, jak i złącze spawane.

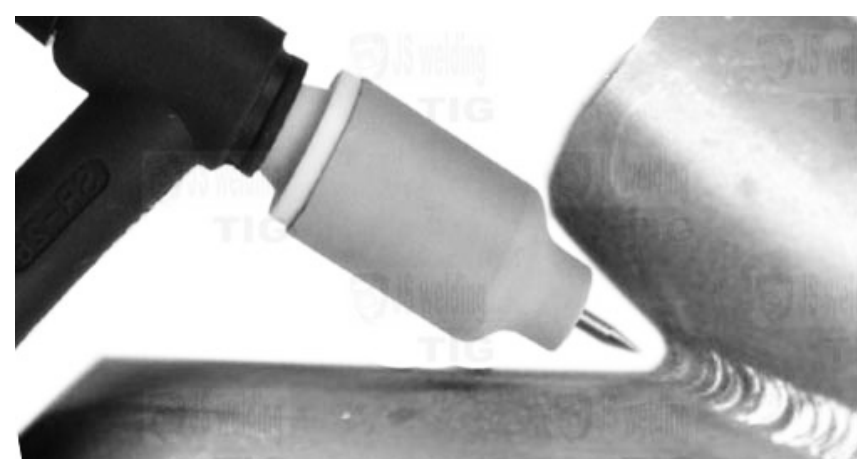

Rys. 6. Schemat spawania trudno dostępnych miejsc [7] Fig. 6. Weld scheme of hard to reach places [7]

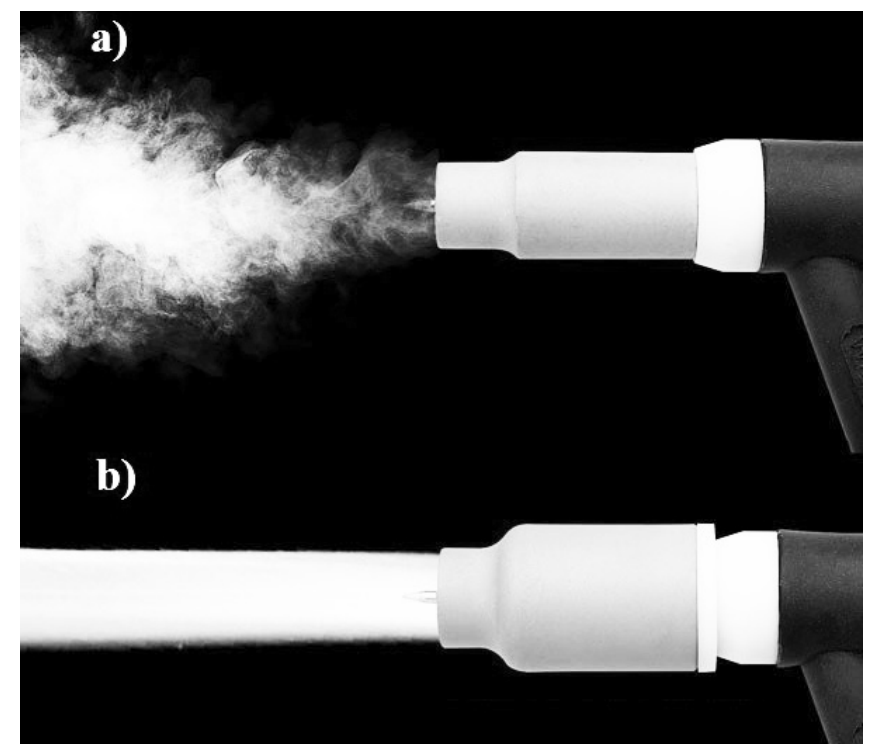

Rys. 7. Wypływ gazu z uchwytu spawalniczego TIG, w którym użyto: a) łącznika prądowego TIG, b) soczewki gazowej [9]

Fig. 7. Gas outflow from the TIG welding handle used: a) coupler switch TIG, b) gas lenses [9]

\section{Badania doświadczalne}

W celu weryfikacji wpływu turbulentnego i laminarnego wypływu gazu osłonowego na uzyskaną jakość spoiny przeprowadzono wstępne badania doświadczalne. Wykonano próbne złącze z materiału X5CrNi1 8-10 (wg PN-EN 10088-1), stosując spawanie metodą TIG z łącznikiem prądowym oraz soczewką gazową. Do wykonania złącza przyjęto stal chromową, ze względu na dużą podatność do wiązania się chromu z tlenem w temperaturach powyżej $200^{\circ} \mathrm{C}$. W przypadku zaburzeń ochrony strefy spawania gazem ochronnym mogą powstawać przebarwienia na skutek utleniania się chromu. Złącze wykonano z użyciem drutu spawalniczego G 199 L Si (wg EN ISO 14343-A) oraz gazu ochronnego I1 (wg PN-EN ISO 14175). Parametry spawania były następujące: prąd spawania - $170 \mathrm{~A}$, napięcie łuku - $11 \mathrm{~V}$, wydatek gazu $-7,5 \mathrm{l} / \mathrm{min}$, przy zastosowaniu dyszy gazowej rozmiaru "9". Na rysunku 8 zobrazowano uzyskane próbki.
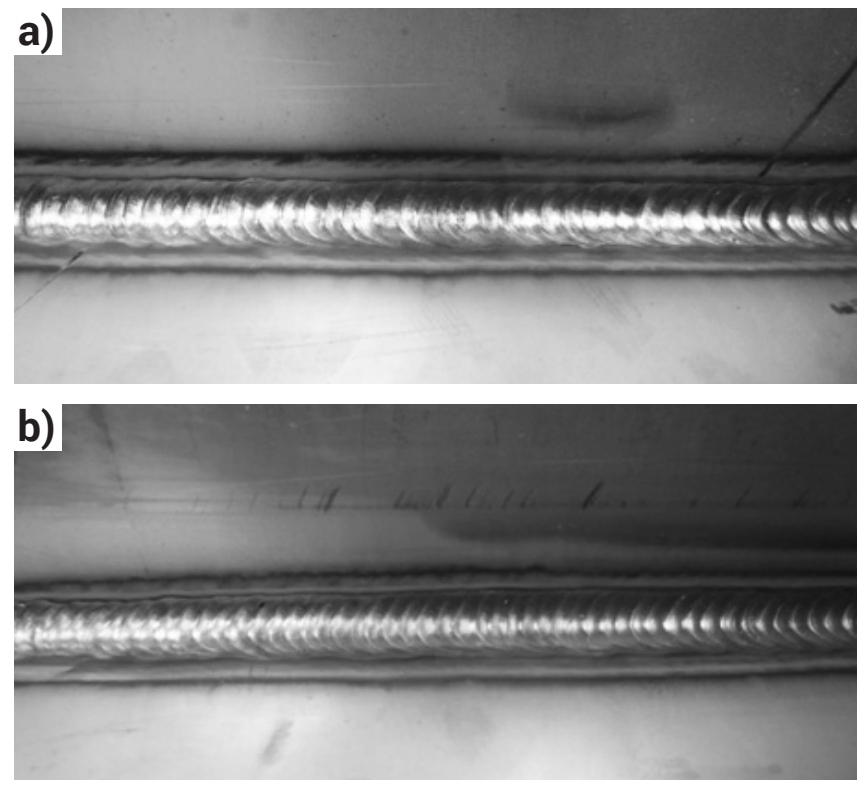

Rys. 8. Obraz złącza spawanego z użyciem: a) łącznika prądowego TIG, b) soczewki gazowej

Fig. 8. Image of a welded joint using: a) coupler switch TIG, b) gas lenses 
Spoina uzyskana spawaniem z zastosowaniem łącznika TIG ma wyraźne przebarwienie, które świadczy o powstaniu warstwy tlenków. Natomiast spoina, którą wykonano z zastosowaniem soczewki gazowej, jest prawie bez przebarwień. Wykonane złącza poddano szczegółowym badaniom wizualnym i penetracyjnym. Na rysunku 9 przedstawiono wynik badania penetracyjnego.

Na podstawie przeprowadzonych badań nieniszczących stwierdzono, że obydwa złącza spełniają poziom jakości B wg PN-EN ISO 5817. Jednak rozpatrując jakość złączy w aspekcie eksploatacyjnym, a w szczególności odporności na korozję, należy stwierdzić, że złącze wykonane z użyciem soczewki gazowej zapewnia większą odporność na korozję. Dla złącza wykonanego z użyciem łącznika TIG utworzona warstwa tlenków w postaci wyraźnego przebarwienia będzie przyczyną korozji.
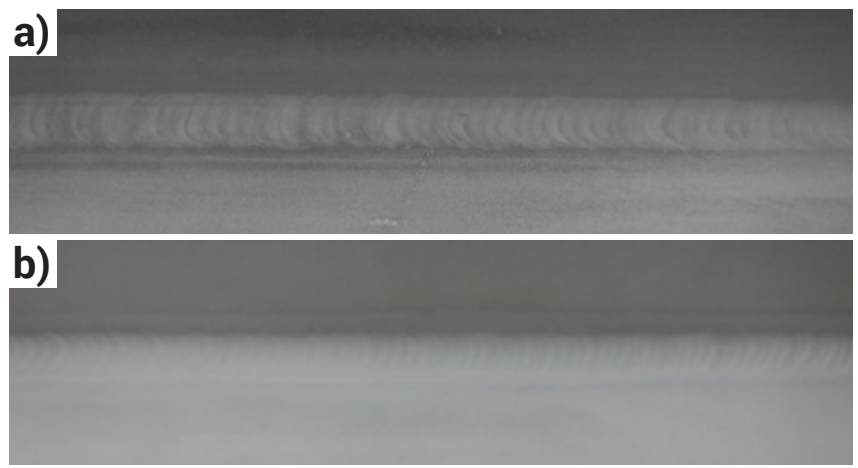

Rys. 9. Obraz z badania penetracyjnego złącza spawanego z użyciem: a) łącznika prądowego TIG, b) soczewki gazowej

Fig. 9. Image of a penetration test of a welded joint using: a) coupler switch TIG, b) gas lenses

\section{Podsumowanie i wnioski}

Przeprowadzona analiza oraz wyniki wstępnych badań doświadczalnych potwierdziły wpływ sposobu wyprowadzania gazu osłonowego w metodzie TIG na jakość złącza spawanego. W przypadku zastosowania łącznika prądowego TIG następuje turbulentny wypływ gazu, co przyczynia się do zaburzeń ochrony strefy spawania gazem ochronnym. W konsekwencji prowadzić to może do dostawania się tlenu do strefy spawania i tworzenia się tlenków - uzyskane wyraźne przebarwienia. Złącza takie w aspekcie cech eksploatacyjnych mogą nie spełniać wymaganej jakości, ponieważ wykazują się dużą podatnością na korozję. Natomiast w przypadku zastosowania soczewki gazowej nie obserwuje się tak wyraźnego tworzenia się warstwy tlenków. Soczewka ułatwia laminarny wypływ gazu z dyszy, który dobrze chroni strefę spawania. Przy wypływie laminarnym dobrze jest chroniona strefa spawania, jednak, aby zachować ciągłość procesu, następuje przemieszczanie łuku spawalniczego wraz ze strumieniem gazu osłonowego, co wpływa na ograniczanie ochrony stygnącej spoiny.

Z uwagi na wstępny charakter badań, należy przeprowadzić szczegółowe badania weryfikacyjne, których wynikiem będą wytyczne w jaki sposób planować i ewentualnie korygować wypływ gazu.

\section{Literatura}

[1] Mizerski J.: Spawanie w osłonie gazów metodą TIG. Podręcznik dla spawaczy i personelu nadzoru spawalniczego, Wydawnictwo REA s. j., Warszawa 2008.

[2] Drabarz M., Chmielewski T.: Wpływ tlenu resztkowego w gazie formujacym na wybrane właściwości grani złącza stali 304L spawanego TIG orbitalnie, Przegląd Spawalnictwa 1/2017, s. 45-50.

[3] Kurpisz B.: Procesy spawania metali, Wydawnictwo KaBe s. c., Krosno 2008.

[4] Kurpisz B.: Spawanie łukowe elektrodą nietopliwą wolframową w osłonach gazu (TIG). Podręcznik dla spawaczy i instruktorów, Wydawnictwo KaBe s.c., Krosno 2016.
[5] Ferenc K.: Spawalnictwo, WNT, Warszawa 2007.

[6] www.waspsupplies.com/ck26-stubby-spares-477-c

[7] www.jswelding.pl/_cms/view/29/spawanie-tig.html

[8] Meka K.: Wymagania spawalnicze dla instalacji rurociągowych w systemach dystrybucji gazów wysokiej czystości w przemyśle półprzewodnikowym, Przegląd Spawalnictwa 5/2015, s. 72-77.

[9] www.eastwood.comtig-welding-10-12-gas-lens-cup-kit.html 